\title{
Management of a Patient with Postural Orthostatic Tachycardia Syndrome, A New Perspective for the Physical Therapist: A Case Report
}

Thomas A. Koc*, Timothy Marshall, Gabriella Fama, Jinal Patel and Jenna Tucker

*Correspondence: tkoc@kean.edu

CrossMark

$\leftarrow$ Click for updates

Kean University, 1000 Morris Ave, Union, NJ 07083, United States of America.

\begin{abstract}
Background: Physical Therapy management of Postural Orthostatic Tachycardia Syndrome (POTS) symptoms is not currently well established.

Purpose: To report the outcomes of a multimodal exercise program for a patient with POTS.

Methods: The patient was a 25 year old female with a primary diagnosis of POTS. The patient attended 30 physical therapy sessions, approximately 60 minutes each, over 12 weeks. The patient participated in a multimodal exercise program (aerobic, functional, and strength) that utilized patient-controlled and therapist-controlled rest intervals. Outcomes were measured every 4 weeks.

Outcomes: Using the SF-36 outcomes, the patient reported the largest improvements between sessions 23-30. These changes in Physical Functioning, Role limitations due to Physical Health, and Pain were $15 \%, 50 \%$, and $22.5 \%$ respectfully. The largest improvements were in average subjective reports of lightheadedness, dizziness, and chest palpitations occurring between visits 1-13 and 14-22, a change of $26.2 \%$.

Conclusion: This was the first study that has investigated a multimodal exercise program (aerobic, functional, strength) that utilized rest interval management as a strategy for exercise progression in a patient diagnosed with POTS. The incorporation of multimodal training methods (aerobic, functional, strength) stimulated positive effects to the parasympathetic nervous system and thus improved average subjective reports of lightheadedness, dizziness, chest palpitations and quality of life in this patient diagnosed with POTS
\end{abstract}

Keywords: POTS, autonomic dysfunction, physical therapy, exercise

\section{Background}

Postural Orthostatic Tachycardia Syndrome (POTS) is currently accepted as a form of autonomic dysfunction and is characterized by the onset of symptoms upon standing such as headaches, fatigue, dizziness, palpitations, sweating, nausea, and syncope [1]. Although presyncope is common in these patients, few individuals experience syncopal episodes; these episodes are commonly relieved by recumbency [2]. Additionally, limited venous return when transitioning from a recumbent position to standing results in the inability to remain upright for long durations [3]. Other autonomic functions that may be affected by POTS include digestion, bladder control, temperature control, sweating, and stress responses. Investigators have found that $25 \%$ of patients with POTS are unable to work due to the presence of these symptoms, which affect the physical, psychological and social aspects of their lifestyle [1].

Although the medical management of POTS is well known, limited research exists regarding physical therapy protocols for patients with this diagnosis. Patients who choose nonpharmacological treatment options may be referred to physi- 
Koc et al, Physical Therapy and Rehabilitation 2020,

http://www.hoajonline.com/journals/pdf/2055-2386-7-1.pdf

doi: $10.7243 / 2055-2386-7-1$

cal therapy for symptom management and a progressive rehabilitation program. Therefore, it is crucial that physical therapists develop treatment strategies to effectively treat this population.

POTS is diagnosed when there is an increase of 30 beats per minute within 10 minutes of standing in the absence of orthostatic hypotension, defined by a decrease in BP $>20 / 10$ $\mathrm{mm} \mathrm{Hg}$ [4]. POTS is more frequent in women than men (ratio, 4.5:1), most commonly between 15 and 25 years of age [2]. The presence of these symptoms for any age/gender group is diagnosed as POTS only when they occur for at least 6 months. POTS may be diagnosed using an active stand test in which heart rate and blood pressure are measured with the patient in supine and standing at intervals of two, five, and ten minutes [1]. However, the preferred method for diagnosing POTS, is with a head-up tilt table test (HUT) where the patient is laying on a table and the head end is gradually lifted to a near upright position, while monitoring heart rate and blood pressure [1].

Many normal physiological changes occur during the transition from supine to standing in patients with POTS. Initially, moving to an upright position rapidly shifts $300-800$ $\mathrm{mL}$ of blood from the thorax into the abdomen and the lower extremities [5]. There is then a secondary shift of plasma volume from the vasculature into the interstitial tissue [4]. These mechanisms result in a reduction in venous return to the heart, central venous pressure and preload on the heart, which decreases stroke volume and cardiac output $[3,6]$. Ultimately, these changes result in inhibition of the parasympathetic nervous system and excitation of the sympathetic nervous system, causing compensatory vasoconstriction and tachycardia. Other causes of compensatory increase in heart rate to maintain cardiac output include generalized deconditioning as well as smaller or less compliant hearts.

Aerobic exercise training for 30-45 minute sessions 2-4 times per week over 12 weeks at $75-85 \%$ of HR-max is known to increase blood volume and cardiac size/mass, and to increase orthostatic tolerance with patients with POTS $[3,6]$. A study by Busmer reported that patients with POTS should participate in 20 minutes of cardiovascular training at least three times per week [1]. Resistance training with weights should begin once weekly for 15-20 minute sessions and then increased to twice weekly, 30-40 minute sessions [6].

Traditionally, management of POTS utilizes established strategies aimed to improve the patient's quality of life using non-pharmacological and pharmacological approaches. Nonpharmacological management commonly includes physical counter maneuvers, increasing sodium and water intake, and wearing support garments. Physical counter maneuvers such as crossing one's legs, tensing muscles, or squatting are advised at the earliest signs of light-headedness and dizziness (presyncope). Performing these maneuvers reduces venous pooling thereby increasing blood pressure [1]. Water intake should be increased to 1.5-2 L daily with sodium intake simultaneously increased to $10 \mathrm{~g}$ per day [2]. Increased salt and water intake is thought to increase circulatory volume and lower heart rate. Support garments such as compression hosiery are advocated to aid venous return [1]. Pharmacological management of POTS includes mineralocorticoids to expand intravascular volume, alpha-1 agonists to elicit peripheral vasoconstriction and reduce venous pooling, and/or beta blockers to control excessive sinus tachycardia [2].

The purpose of this case presentation is to report the outcomes of a multimodal exercise program for a patient with POTS.

\section{Case Presentation}

The patient was a 25 year-old female reporting progressive syncopal episodes with lightheadedness, dizziness, and chest palpitations that occurred with increasing frequency over two years. The patient was diagnosed with Postural Orthostatic Tachycardia Syndrome (POTS) two weeks prior to starting physical therapy, with a history of Ehler-Danlos Syndrome from age 19. The patient's physician advised her to begin pharmacological treatment using a beta-blocker, however, she requested non-pharmacological options and was referred to physical therapy. The patient reported the onset of lightheadedness and dizziness when standing for 15-20 minutes, using the strategy of performing a half or full squat and/or performing deep breathing to prevent a syncopal episode. The patient's goal for physical therapy was "to have less pain, to function better, and to stop myself from fainting". This study was conducted in accordance with the Declaration of Helsinki 1964 and sufficient informed consent was obtained from the patient, paying attention to the Health Insurance Portability and Accountability Act (HIPAA) of 1996.

\section{Methods}

The patient attended physical therapy for 30 sessions, approximately 60 minutes each, over 12 weeks. The authors define "primary focus" as constituting $>30$ minutes of activity per session and secondary focus as constituting $<30$ minutes of activity. The treatment approach from visits 1-13 was primarily focused on aerobic training and secondarily focused on functional training. Visits 14-22 primarily focused on functional training and secondarily focused on aerobic training. Visits 23-30 primarily focused on strengthening and secondarily focused on functional training. Throughout visits 1-22 the patient controlled the rest intervals in which she began the next activity when she felt comfortable. From sessions 23-30, the physical therapist controlled rest intervals with a gradual reduction in duration of time between activities. Controlled rest intervals were set as: 1:3 when targeting the phosphagen system, 1:2 when targeting the short-term glycolytic energy system, or 1:1 when targeting the long-term aerobic energy system [7]. Examples of aerobic activities included upright bike, Alter- $\mathrm{G}^{\mathrm{TM}}$, and the upper body ergometer (UBE). Examples of functional training included squats, deadlifts, resisted lateral 
steps, lunges, turkish get ups, and forward/rotational step ups. Examples of strengthening activities included bridges, clamshells, lat pull downs, rows, biceps curls, tricep extensions, planks, and calf raises; these activities utilized bodyweight, resistance bands or dumbbells as appropriate.

The 36- Item Short Form Health Survey (SF-36) is a selfreport questionnaire used to assess the quality of life in various medical populations [8]. The patient completed the SF-36 at visits $1,13,22$, and 30 .

\section{Outcomes}

Overall the SF-36 components with notable improvement that correlated to the patient's goals occurred between visits 23-30 and included: Physical Functioning, Role limitations due to Physical Health, and Pain (Table 1). The patient's subjective reports of symptoms, which included dizziness, lightheadedness and chest palpitations were averaged from visits 1 to 13 , 14 to 22 , and 23 to 30 (Table 2).

While observing the SF-36 outcomes, the patient reported the largest improvements were between sessions 23-30. These changes in Physical Functioning, Role limitations due to Physical Health, and Pain were, $15 \%, 50 \%$, and $22.5 \%$ respectfully. The primary focus of these visits was strength training and secondarily focused on functional activity training.The largest improvements in average subjective reports of lightheadedness, dizziness, and chest palpitations was between visits $1-13$ and $14-22$, a change of $26.2 \%$. The primary focus of these visits was functional training and secondarily focused on aerobic training.

\section{Discussion}

To our knowledge, this is the first case study to assess a physical therapy treatment plan that utilizes rest break management as a strategy for exercise progression in a patient diagnosed with POTS. This patient initially presented with symptoms of syncope resulting in negative effects on the quality of life. She participated in a multimodal exercise program which initially utilized patient-controlled rest breaks and progressed to therapist-controlled rest intervals over 30 visits. At the conclusion of the treatment, the patient demonstrated improved exercise tolerance and reported improved quality of life, as indicated by the score on the SF-36.

The changes observed in the present case study may be explained by previous research that demonstrated aerobic exercise training over a 12-week period has positive influences on the parasympathetic nervous system and that lowering heart rate variability is thought to be a reflection of cardiac autonomic modulation [9]. Physical training improved parasympathetic nervous activity in both patients who were healthy and with acute myocardial infarctions [10]. Aerobic exercise training improved cardiac autonomic imbalances by increasing parasympathetic and/or decreasing sympathetic

Table 1. Summary of SF-36 scores per visit range.

\begin{tabular}{|c|c|c|c|c|c|c|c|c|}
\hline Category & $\begin{array}{l}\text { Initial } \\
\text { Evaluation } \\
\text { (IE) }\end{array}$ & $\begin{array}{l}\text { Progress } \\
\text { Note \#1 } \\
(\mathrm{PN}) \\
\end{array}$ & $\begin{array}{l}\text { Progress } \\
\text { Note \#2 } \\
(\mathrm{PN}) \\
\end{array}$ & $\begin{array}{l}\text { Discharge } \\
\text { Note (DN) }\end{array}$ & $\begin{array}{l}\text { Health Change } \\
\text { from Visits } \\
1-13\end{array}$ & $\begin{array}{l}\text { Health Change } \\
\text { from Visits } \\
14-22 \\
\end{array}$ & $\begin{array}{l}\text { Health Change } \\
\text { from Visits } \\
23-30 \\
\end{array}$ & $\begin{array}{l}\text { Health Change } \\
\text { from Visits } 1 \\
\text { to } 30\end{array}$ \\
\hline $\begin{array}{l}\text { Physical } \\
\text { Functioning }\end{array}$ & $82.5 \%$ & $80.0 \%$ & $80.0 \%$ & $95.0 \%$ & $-2.5 \%$ & $0.0 \%$ & $15.0 \%$ & $12.5 \%$ \\
\hline $\begin{array}{l}\text { Role } \\
\text { limitations due to } \\
\text { physical health }\end{array}$ & $50.0 \%$ & $50.0 \%$ & $25.0 \%$ & $75.0 \%$ & $0.0 \%$ & $-25.0 \%$ & $50.0 \%$ & $25.0 \%$ \\
\hline $\begin{array}{l}\text { Role of limitations } \\
\text { due to emotional } \\
\text { problems }\end{array}$ & $67.0 \%$ & $67.0 \%$ & $80.0 \%$ & $100.0 \%$ & $0.0 \%$ & $13.0 \%$ & $20.0 \%$ & $33.0 \%$ \\
\hline Energy \& Fatigue & $55.0 \%$ & $55.0 \%$ & $75.0 \%$ & $75.0 \%$ & $0.0 \%$ & $20.0 \%$ & $0.0 \%$ & $20.0 \%$ \\
\hline $\begin{array}{l}\text { Emotional } \\
\text { well-being }\end{array}$ & $84.0 \%$ & $80.0 \%$ & $45.0 \%$ & $80.0 \%$ & $-4.0 \%$ & $-35.0 \%$ & $35.0 \%$ & $-4.0 \%$ \\
\hline Social Functioning & $100.0 \%$ & $75.0 \%$ & $75.0 \%$ & $87.5 \%$ & $-25.0 \%$ & $0.0 \%$ & $12.5 \%$ & $-12.5 \%$ \\
\hline Pain & $40.0 \%$ & $35.0 \%$ & $45.0 \%$ & $67.5 \%$ & $-5.0 \%$ & $10.0 \%$ & $22.5 \%$ & $27.5 \%$ \\
\hline General health & $60.0 \%$ & $30.0 \%$ & $50.0 \%$ & $40.0 \%$ & $-30.0 \%$ & $20.0 \%$ & $-10.0 \%$ & $-20.0 \%$ \\
\hline
\end{tabular}

Table 2. Summary of average subjective reports per visit range and goals during each session.

\begin{tabular}{llll}
\hline & Primary Goal during session & Secondary Goal during session & Average Subjective rating reports \\
\hline Visits: $1-13$ & Aerobic Training & Functional Activity Training & $60.60 \%$ \\
Visits: $14-22$ & Functional Activity Training & Aerobic Training & $34.40 \%$ \\
Visits: $23-30$ & Strength Training & Functional Activity Training & $29.90 \%$ \\
\hline
\end{tabular}


Koc et al, Physical Therapy and Rehabilitation 2020,

http://www.hoajonline.com/journals/pdf/2055-2386-7-1.pdf

activity [11]. Physical activity promoted favorable physiologic adaptations, leading to an improvement of quality of life [12].

With the support of previous studies, the authors theorize that improvements in the: (1) patient's average subjective reports, (2) scores of Physical Functioning, Role limitations due to Physical Health, Energy/Fatigue and (3) Pain on the SF-36, were a result of improved parasympathetic tone. We also theorize that the improvement in parasympathetic tone was: (1) primarily from the aerobic training components, (2) secondarily the functional and strength training and (3) the decreasing time of rest intervals between exercises utilized during the patient's 12 -week rehabilitation. The authors completed an extensive literature review which revealed a lack of research articles regarding the effects of reducing rest intervals during exercise training to improve modulation of the parasympathetic nervous system.

\section{Limitations}

There are several limitations to this study. First, the small sample size restricts our ability to generalize outcomes to all patients diagnosed with POTS. A second limitation is our inability to determine which modes of exercise correlated to the greatest improvements in average subjective reports and on the SF-36; this is due to the incorporation of multimodal training methods (aerobic, functional, strength). Lastly, although the SF-36 has been validated for patients with cardiac conditions and has been used in previous research for patients with POTS, it has not been validated specifically for POTS $[6,13]$.

\section{Conclusion}

In conclusion, the authors theorize that the incorporation of multimodal training methods (aerobic, functional, strength) stimulate positive effects to the parasympathetic nervous system and thus improve average subjective reports of lightheadedness, dizziness, chest palpitations and quality of life in this patient diagnosed with POTS.

\section{Competing interests}

The authors declare that they have no competing interests.

Authors' contributions

\begin{tabular}{|l|c|c|c|c|c|}
\hline Authors' contributions & TAK & TM & GF & JP & JT \\
\hline Research concept and design & $\checkmark$ & $\checkmark$ & -- & -- & -- \\
\hline Collection and/or assembly of data & $\checkmark$ & -- & -- & -- & -- \\
\hline Data analysis and interpretation & $\checkmark$ & $\checkmark$ & $\checkmark$ & $\checkmark$ & $\checkmark$ \\
\hline Writing the article & $\checkmark$ & $\checkmark$ & $\checkmark$ & $\checkmark$ & $\checkmark$ \\
\hline Critical revision of the article & $\checkmark$ & $\checkmark$ & $\checkmark$ & $\checkmark$ & $\checkmark$ \\
\hline Final approval of article & $\checkmark$ & $\checkmark$ & $\checkmark$ & $\checkmark$ & $\checkmark$ \\
\hline Statistical analysis & $\checkmark$ & -- & -- & -- & $\checkmark$ \\
\hline
\end{tabular}

Publication history

Editor: Gordon John Alderink, Grand Valley State University, USA. Received: 03-Dec-2019 Final Revised: 01-Feb-2020

Accepted: 05-Feb-2020 Published: 16-Feb-2020

\section{References}

1. Busmer L. Diagnosis and management of postural tachycardia syndrome. Nurs Stand. 2013; 27:44-8. | Article | PubMed

2. Benarroch EE. Postural tachycardia syndrome: a heterogeneous and multifactorial disorder. Mayo Clin Proc. 2012; 87:1214-25. | Article | PubMed Abstract I PubMed FullText

3. Richardson MVPDGC, Nordon-Craft APD and Carrothers LPP. Using an exercise program to improve activity tolerance in a female with postural orthostatic tachycardia syndrome: A case report. Physiother Theory Pract. 2017; 33:670-679. I Article I PubMed

4. Raj SR. Postural tachycardia syndrome (POTS). Circulation. 2013; 127:2336-42. | Article | PubMed Abstract | PubMed FullText

5. Carew S, Connor MO, Cooke J, Conway R, Sheehy C, Costelloe A and Lyons D. A review of postural orthostatic tachycardia syndrome. Europace. 2009; 11:18-25. I Article I PubMed

6. Fu Q, Vangundy TB, Galbreath MM, Shibata S, Jain M, Hastings JL, Bhella PS and Levine BD. Cardiac origins of the postural orthostatic tachycardia syndrome. J Am Coll Cardiol. 2010; 55:2858-68. | Article I PubMed Abstract | PubMed FullText

7. McArdle W, Katch F and Katch V. Training for Anaerobic and Aerobic Power, in: Exercise Physiology: nutrition, energy, and human performance, eighth ed. Wolters Kluwer Health/Lippincott Williams \& Wilkins. Baltimore, Maryland, Ch. 21. 2010: 488.

8. Benrud-Larson LM, Dewar MS, Sandroni P, Rummans TA, Haythornthwaite JA and Low PA. Quality of life in patients with postural tachycardia syndrome. Mayo Clin Proc. 2002; 77:531-7. | Article | PubMed

9. Amano M, Kanda $\mathrm{T}$, Ue $\mathrm{H}$ and Moritani T. Exercise training and autonomic nervous system activity in obese individuals. Med Sci Sports Exerc. 2001; 33:1287-91. I Article I PubMed

10. Oya M, Itoh H, Kato K, Tanabe K and Murayama M. Effects of exercise training on the recovery of the autonomic nervous system and exercise capacity after acute myocardial infarction. Jpn Circ J. 1999; 63:843-8. | Article I PubMed

11. Billman GE. Cardiac autonomic neural remodeling and susceptibility to sudden cardiac death: effect of endurance exercise training. Am J Physiol Heart Circ Physiol. 2009; 297:H1171-93. I Article I PubMed

12. Morais MJD, Raimundo RD, Oliveira FS, Abreu LC, Bezerra IMP, Silva RPM, Rodrigues AS, Valenti VE and Perez-Riera AR. Evaluation of the effects of aerobic training during hemodialysis on autonomic heart rate modulation in patients with chronic renal disease. Medicine (Baltimore). 2019; 98:e15976. | Article | PubMed Abstract | PubMed FullText

13. Bjorner JB, Wallenstein GV, Martin MC, Lin P, Blaisdell-Gross B, Tak Piech $\mathrm{C}$ and Mody $\mathrm{SH}$. Interpreting score differences in the SF-36 Vitality scale: using clinical conditions and functional outcomes to define the minimally important difference. Curr Med Res Opin. 2007; 23:731-9. | Article I PubMed

\section{Citation:}

Koc TA, Marshall T, Fama G, Patel J and Tucker J. Management of a Patient with Postural Orthostatic Tachycardia Syndrome, A New Perspective for the Physical Therapist: A Case Report.

Phys Ther Rehabil. 2020; 7:1.

http://dx.doi.org/10.7243/2055-2386-7-1 